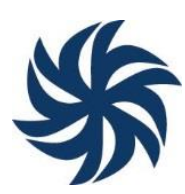

\title{
ANÁLISE DA REDE DE PRODUÇÃO DE CONHECIMENTO SOBRE A INICIATIVA E-DEMOCRACIA
}

\section{ANALYSIS OF THE KNOWLEDGE PRODUCTION NETWORK OF THE INITIATIVE E-DEMOCRACIA}

\author{
ANÁLISIS DE LA RED DE PRODUCCIÓN DE CONOCIMIENTO SOBRE LA \\ INICIATIVA E-DEMOCRACY
}

\author{
Christiana Soares de Freitas ${ }^{1}$ \\ Rafael Cardoso Sampaio ${ }^{2}$ \\ Henrique Machado ${ }^{3}$ \\ Ricardo Sampaio ${ }^{4}$ \\ Tiago Borges 5 \\ Murilo Brum Alison ${ }^{6}$ \\ Djiovanni Jonas França Marioto ${ }^{7}$
}

Resumo: O artigo visa à análise de produções acadêmicas que analisaram o programa de inovação democrática e-Democracia, da Câmara dos Deputados, de 2009 a 2017. Foram aplicadas três metodologias de análise, nomeadamente: análise de conteúdo para identificação de autores, instituições e áreas de conhecimento; análise léxica de resumos e palavras-chave através do software IRaMuTeQ e análise de redes das referências bibliográficas dos materiais. Os resultados indicam que esse subcampo apresenta algumas diferenças em relação à área de internet e política (I\&P) no Brasil, especialmente no que tange a instituições e áreas de atuação, porém a rede de cocitações revela que autores-chave da grande área de I\&P também são centrais aqui. Conclui-se que esta subárea apresenta particularidades em relação ao campo, como a entrada de novas instituições e áreas de conhecimento. São mantidas, contudo, as principais linhas de pesquisa e autores da grande área de internet e política.

Palavras-chave: Democracia Digital; e-Democracia; Parlamento Aberto; Cientometria.

Abstract: The article aims at analyzing the academic production - from 2009 to 2017 - regarding a democratic innovation program developed by the Brazilian Chamber of Deputies called e-Democracia. Three methodologies were applied: content analysis to identify institutions, authors and knowledge areas; lexical analysis of keywords and abstracts of the produced material by using the software IRaMuTeQ; and network analysis of the bibliographical references. Results indicate that this subfield has some differences in contrast to Brazilian Internet and Politics field (I\&P), especially regarding the presence of new and non-traditional institutions and areas of knowledge analyzing the e-Democracia initiative. Nevertheless,

\footnotetext{
${ }^{1}$ Professora de Direito e Gestão de Políticas Públicas da Universidade de Brasília (UnB) e líder do Grupo de Pesquisa sobre Estado, Regulação, Internet e Sociedade (GERIS/UnB). Email: freitas.christiana@gmail.com. Orcid iD: http://orcid.org/0000-0003-0923-843X

${ }^{2}$ Professor do Departamento e do Programa de Pós-Graduação em Ciência Política da Universidade Federal do Paraná (UFPR) e colíder do Laboratório de Análise do Campo Científico (LaCC-UFPR). E-mail: cardososampaio@gmail.com. Orcid iD: http://orcid.org/0000-0001-5176-173X

3 Mestre em Direito da Faculdade de Direito da Universidade de Brasília (FD/UnB). E-mail: henriquefsmachado@gmail.com. Orcid iD: https://orcid.org/0000-0002-6407-7918

${ }^{4}$ Pesquisador da Fiocruz/Brasília e Professor de Ciências da Informação da Universidade de Brasília (UnB). E-mail: rbsam@unb.br. Orcid iD: https://orcid.org/0000-0002-6989-8555

${ }^{5}$ Mestrando do Programa de Pós-Graduação em Ciência Política da Universidade Federal do Paraná e integrante do LaCC. E-mail: tpfbsilva@gmail.com Orcid iD: https://orcid.org/0000-0001-9647-8225

${ }^{6}$ Mestrando do Programa de Pós-Graduação em Ciência Política da Universidade Federal do Paraná e integrante do LaCC. E-mail: murilo43@ @otmail.com. Orcid iD: https://orcid.org/0000-0001-9224-1407

${ }^{7}$ Mestrando do Programa de Pós-Graduação em Ciência Política da Universidade Federal do Paraná e integrante do LaCC. E-mail: djiovannimarioto@gmail.com. Orcid iD: https://orcid.org/0000-0002-6485-5927
} 
the cocitation network revealed that key authors of the I\&P field are central in the analyzed subfield as well. The main research topics and authors of the wider field of Internet and Politics are also similar to the ones identified in digital democracy studies.

Keywords: Digital Democracy; e-Democracia; Open Parliament; Scientometrics.

Resumen: El artículo tiene como objetivo analizar producciones académicas que analizaron el programa de innovación democrática e-Democracia de la Cámara de Diputados, de 2009 a 2017. Se aplicaron tres metodologías de análisis, a saber: análisis de contenido para identificar autores, instituciones y áreas de conocimiento; análisis léxico de resúmenes y palabras clave a través del software IRaMuTeQ y análisis de red de referencias bibliográficas de materiales. Los resultados indican que este subcampo presenta algunas diferencias en relación con el área de internet y política (I\&P) en Brasil, especialmente en relación con las instituciones y áreas de actividad, pero la red de cocitation revela que los autores clave del área grande de I\&P también son centrales aquí. Se concluye que esta subárea presenta particularidades en relación con el campo, como la entrada de nuevas instituciones y áreas de conocimiento. Sin embargo, se mantienen las principales líneas de investigación y autores del área principal de internet y política.

Palabras clave: Democracia digital; e-democracia; Parlamento abierto; Scientometry

\section{Introdução}

O objetivo desse artigo é compreender o desenvolvimento de subcampos de estudos e pesquisas sobre democracia digital a partir da análise do e-Democracia - uma inovação democrática participativa brasileira - e de seu progressivo reconhecimento como objeto relevante de pesquisa. O programa - sob a forma de um portal denominado e-Democracia - foi lançado em 2009 por iniciativa da Câmara dos Deputados do Brasil. Foi desenvolvida com o objetivo de oferecer aos cidadãos brasileiros canais de comunicação e interação com os deputados, além de oferecer um instrumento específico para a construção compartilhada de projetos de lei (FARIA, 2012, 2015, 2016; FREITAS; FIUZA; QUEIROZ, 2015; MITOZO et al, 2016). Com o intuito de observar tendências nesse subcampo foi realizado, inicialmente, um mapeamento dos autores que se debruçaram sobre a iniciativa, os temas e subtemas mais relevantes e os tipos de trabalhos produzidos. De especial interesse foram as análises das relações entre pesquisadores a partir da rede de citações e cocitações, identificando as principais áreas do conhecimento e instituições envolvidas.

A curiosidade inicial nasceu da constatação de uma produção considerável sobre o eDemocracia nos últimos anos, da sua visibilidade significativa e, com isso, uma produção acadêmica - e não acadêmica - crescente. $\mathrm{O}$ e-Democracia passou a constituir-se como objeto de análise com consistência e estabilidade suficientes para mensurações e aplicação de metodologias variadas. A iniciativa tem como objetivo central incentivar a participação da sociedade no debate de diversos temas relacionados às demandas cidadãs, podendo vir a transformar essa participação em processos de produção colaborativa de projetos de lei.

Segundo o seu principal idealizador, os objetivos do e-Democracia incluem melhorar a interação entre a sociedade e a Câmara dos Deputados, fortalecer o papel do Poder Legislativo na formulação de políticas públicas, estimular a participação social responsável e construtiva, 
melhorar a compreensão da sociedade brasileira sobre a complexidade do trabalho legislativo e aumentar a transparência relativa ao processo (FARIA, 2012, p. 185). Portanto, apesar de seu foco mais imediato ser na e-participação, o e-democracia também apresenta ferramentas e processos diretamente relacionados a outros valores democráticos, como deliberação pública, transparência e representação.

A pesquisa em tela analisou 62 materiais acadêmicos (como artigos, papers, monografias, dissertações, relatórios etc.) publicados (ou apresentados) no Brasil entre 2009 e 2017 que apresentaram o e-Democracia como objeto central de discussão, observação e reflexão. Foi realizada, inicialmente, análise de conteúdo quantitativa de aspectos gerais das produções acadêmicas, como autores/as, instituições e áreas de atuação. Depois, os resumos e palavras-chave disponíveis de todos os materiais foram analisados por meio de uma análise léxica automatizada, realizada pelo software $I R a M u T e Q$, o que nos permitiu identificar temas e palavras-chave da produção. Finalmente, foi feita análise de redes com as referências bibliográficas de todos os materiais para permitir uma melhor compreensão sobre redes de autores e mesmo da existência de escolas de pensamento específicas.

Os resultados iniciais indicam que novas instituições ganham destaque nos estudos sobre democracia digital em comparação à grande área de internet e política (I\&P) no Brasil (SAMPAIO et al, 2016), assim como outras áreas de atuação aparecem com mais frequência. No entanto, pela análise das palavras-chave e pelas redes de cocitação, há indícios de que seja uma subárea bastante similar ao campo de I\&P.

\section{Internet e política na pesquisa brasileira}

A maioria dos estudos do campo de Internet e Política (I\&P), área em que os estudos sobre o e-Democracia se inserem, tende a não focar diretamente no conceito de democracia digital, excetuando-se o levantamento de Curtinovi e Parmeggiani (2015). No geral, ou se parte para uma avaliação aberta (estudos sobre internet e política) ou os esforços concentram-se na elaboração de conceitos mais especializados dentro da literatura de democracia digital, como é o caso do ciberativismo, da deliberação on-line e de formas específicas de e-participação.

Em perspectiva mais ampla, o estudo de Sampaio, Bragatto e Nicolás (2016) tem a preocupação de entender a formação do campo de Internet e Política (I\&P) como um subcampo da Comunicação e Política no Brasil. O estudo avalia 526 artigos de 11 eventos na área de Comunicação Social, Ciência Política, Sociologia e Ciências Sociais entre 2000 e 2014.

Se 1996 é um ano divisor de águas na literatura internacional sobre democracia digital, a literatura brasileira parece demorar uma década a mais. Até o ano de 2005, segundo Sampaio et al (2016), os artigos não superavam $2 \%$ do total. O crescimento ocorre de maneira mais significativa a partir de 2006 (3,8\%). Por sua vez, o período entre 2012 e 2014 representa 43,1\% 
do total de artigos analisados, o que evidencia um rápido crescimento da produção nos últimos anos, provavelmente incentivados pelos estudos de redes sociais on-line (GOMES, 2016).

No que tange a instituições e autores, o estudo de Sampaio et al (2016) aponta que há consideravelmente mais autores da área de Comunicação $(45,6 \%)$ do que da ciência política $(13,9 \%)$, ciências sociais $(8,0 \%)$ e sociologia $(7,4 \%)^{8}$, sendo a maioria já doutores $(30 \%)$. Ainda assim, mestrandos $(26,4 \%)$ e doutorandos $(19,4 \%)$ representam quase metade da população analisada. Interessante observar que algumas das universidades mais tradicionais do país não estão entre as principais produtoras da literatura de I\&P.

As quatro instituições que lideram a produção de artigos são a Universidade Federal da Bahia (UFBA, 9,7\%), a Pontifícia Universidade Católica do Estado de São Paulo (PUC-SP, 8,9\%), a Universidade Federal de Minas Gerais (UFMG, 6,5\%) e a Universidade Federal do Paraná (UFPR, 6,5\%). Isso não significa uma alteração significativa da predominância de produção por regiões. A região sudeste mantém uma concentração da literatura $(45,8 \%)$, seguida pelas regiões Nordeste $(14,1 \%)$ e Sul $(13,8 \%)$, o que se explica pela notabilidade de UFBA e UFPR, respectivamente (SAMPAIO; BRAGATTO; NICOLÁS, 2016).

O estudo de Santos, Aldé e Schwambach (2016) pode ser particularmente rico para explicar a situação. Diferentemente do estudo anterior, baseado em artigos de eventos, os autores fizeram análise de dissertações e teses da área de Comunicação e Política focadas em Internet e Política. O corpus dessa pesquisa é consideravelmente menos extenso que a anterior, compreendendo 59 produções, porém é mais abrangente longitudinalmente, compreendendo o período entre 1992 e 2014. Outra diferença marcante em relação ao trabalho de Sampaio et al (2016) é a preocupação maior com a literatura acionada pelos autores, assim como características específicas desse tipo de produção científica, como orientadores e membros da banca.

Segundo Santos, Aldé, Schwambach (2016), as cinco universidades com maior produção são UFBA (13), UFF (8), UFMG (6), PUC-SP (8) e UERJ (7), o que reforça o dado já apontado na pesquisa anterior, mostrando que UFBA, UFMG e PUC-SP são, de fato, grandes centros de pesquisa da área de I\&P. Ademais, revela como o estado do Rio de Janeiro apresenta produção considerável.

Santos e seus co-autores (2016) apontam, ainda, que não é apenas a produção considerável dos pesquisadores nestas universidades que chama a atenção, mas também a capacidade de orientação desses pesquisadores, apontando para a capacidade de formar novos profissionais atuantes na área9 ${ }^{9}$. Além de orientadores e participantes de bancas, o estudo de

\footnotetext{
${ }^{8}$ O trabalho de Curtinovi e Parmeggiani (2015) também evidencia a preponderância da área de Comunicação (47\%) sobre Ciência Política (18\%) e Ciências Sociais (5\%).

9 A presença de Wilson Gomes, na UFBA (8 orientações), Vera Chaia, na PUC-SP (6 orientações), Afonso de Albuquerque, na UFF (5 orientações), Alessandra Aldé, na UEJR (5 orientações) e Rousiley Maia, na UFMG (5 orientações) explica a alta produção nestas universidades em ambas as pesquisas.
} 
Santos et al (2016) também demonstra como estes mesmos pesquisadores (em conjunto com seus orientandos) se tornam os mais referenciados pela própria literatura. Foram identificados 3.632 autores diferentes acionados, porém apenas 1.193 são utilizados mais de uma vez e apenas 24 autores são citados mais de 30 vezes $^{10}$.

No que se refere aos temas, o estudo de Sampaio, Bragatto, Nicolás (2016) evidencia o maior interesse nacional pela vertente social $(58,9 \%)$ do que pela institucional $(41,1 \%)$, o que confirma o achado de Gomes (2016) em relação ao crescente interesse internacional pelo tema de "internet e sociedade" (37\%) dentro da temática sobre política digital. O estudo também confirma que a literatura nacional sobre Internet e Política parece dedicar boa parte de seus esforços a temáticas diretamente relacionadas à democracia digital, a exemplo do que ocorre na literatura internacional (GOMES, 2016).

As abordagens conceituais nacionais mais recorrentes foram "participação" (20,7\%), "engajamento" (18,3\%), e "deliberação" (9,7\%). Outras questões mais proeminentes da democracia digital, como "transparência" (4,2\%), "inclusão digital" $(5,1 \%)$, "identidade e cidadania" (5,3\%) e "accountability" (2,1\%) também foram identificadas. Isso não significa a ausência da política digital, presente em temas como "estratégia política e eleitoral" (9,5\%), "economia política da comunicação" $(6,8 \%)$ e "representação política" (2,7\%) - (SAMPAIO et $a l$, 2016). Os mesmos temas aparecem como centrais nos trabalhos analisados sobre o eDemocracia, como será discutido nos resultados da pesquisa aqui apresentada.

Dentro dessas abordagens conceituais, o estudo de Sampaio et al também avalia qual o objeto político em foco nos artigos, chegando aos seguintes dados: "esfera civil não-organizada" (27,6\%), "governo" (24,3\%), "movimentos sociais" (17,9\%), “campanhas eleitorais" (13,7\%). Tais números evidenciam que a maior parte da literatura brasileira lida com questões relacionadas à esfera civil, seja sob a forma de ações políticas mais espontâneas e/ou mantidas pelo cidadão não organizado, seja com foco em organizações cívicas e movimentos sociais. Não obstante, tanto o foco em governo quanto em campanhas evidencia que as questões institucionais também são relevantes para os estudos de I\&P brasileiros.

Números semelhantes são vistos nas temáticas identificadas por Santos et al (2016). Dentre os trabalhos analisados, destacam-se 52 relacionados à "Comunicação e Sociedade Civil"; 38 se enquadram em propostas de "Comunicação e Democracia"; 25 estão entre os trabalhos de "Políticas de Comunicação"; 17 relacionam-se à "Mídia e Eleições" e 16 à "Cultura Política, Comportamento e Opinião Pública". Portanto, a temática "internet e sociedade" também recebe maior atenção da área de I\&P no Brasil, como ocorre na literatura

\footnotetext{
${ }^{10}$ Retirando-se as referências estrangeiras, os autores mais acionados são: Wilson Gomes (187), Rousiley Maia (101), Francisco Jamil Marques (99), Sérgio Braga (60), André Lemos (49), Rafael Cardoso Sampaio (46), Leonardo Avritzer (41), Luis Felipe Miguel (36), Raquel Recuero (36), Alessandra Aldé (36), Sivaldo Pereira da Silva (31) e Maria Alejandra Nicolas (31), confirmando o papel central destes pesquisadores na literatura brasileira. É notável, também, que a maior parte dos autores integra a rede de pesquisa do Instituto Nacional de Ciência e Tecnologia em Democracia Digital (INCT.DD).
} 
internacional.

Por sua vez, não se pode ignorar que, em diversos pontos, os estudos sobre democracia digital convergem com os de governo eletrônico (PINHO, 2008). A avaliação mais completa da área foi realizada por Przeybilovicz, Cunha e Coelho (2015), aonde buscaram verificar de maneira ampla a produção sobre governo eletrônico na área de Administração no Brasil. Para tanto, os autores prospectaram os principais eventos da área ${ }^{11}$ e também a produção de periódicos classificados pela CAPES com conceito igual ou acima de B2 na área de Administração (2012) no período entre 2007 e 2012, o que resultou em 124 artigos, envolvendo 84 instituições, somando 188 coautorias.

Aqui, pelo foco em Administração, as instituições líderes são notadamente diferentes daquelas apresentadas por Sampaio et al (2016) e Santos et al (2016), permanecendo apenas a UFBA entre as cinco maiores produtoras de pesquisa, conforme os dados a seguir: Universidade de São Paulo (17,7\%), Universidade Federal da Bahia (9,7\%), Pontifícia Universidade Católica do Paraná (8,9\%), Fundação Getúlio Vargas (8,1\%) e Universidade de Brasília (6,5\%). Através de uma análise de rede das instituições com base nos autores, o estudo aponta para uma alta centralidade da USP, que funciona como um elo para instituições de várias regiões do Brasil. Ademais, destacam-se outras redes regionais, notadamente a PUC-PR que se conecta a pesquisadores do Sul, a Universidade Federal de Santa Catarina (UFSC) a instituições de seu estado, a Universidade Federal da Paraíba (UFPB) a instituições do nordeste e centro-oeste e Fundação Getúlio Vargas a instituições não acadêmicas.

A análise de Przeybilovicz, Cunha e Coelho (2015) também evidencia que a maior parte da literatura de Administração no Brasil, de fato, se preocupa, centralmente, com governo eletrônico $(n=33)$ e e-administração $(n=25)$; porém, também há espaço para subtemas da democracia digital, como a e-governança $(n=9)$, a e-participação $(n=8)$ e para a própria edemocracia $(n=6)$.

Nesse artigo, o objetivo é justamente verificar algumas das possíveis diferenças existentes quando o campo visa à compreensão e estudo de um objeto específico.

\section{Metodologia}

A pesquisa que originou esse artigo teve como objetivo central compreender o campo de democracia digital a partir da análise da produção bibliográfica existente sobre a iniciativa eDemocracia da Câmara dos Deputados. O lançamento do portal e-Democracia pela Câmara dos Deputados surge a partir de um núcleo técnico da Casa diferente daquele responsável pelo Portal da Câmara (MITOZO et al, 2016). O projeto começou em um formato piloto, possuindo

\footnotetext{
${ }^{11}$ Encontro da Associação Nacional de Pós-graduação e Pesquisa em Administração (EnANPAD), Encontro de Administração da Informação (EnADI), VII Encontro de Administração Pública da ANPAD (EnAPG) e International Conference on Information Systems and Technology Management (CONTECSI).
} 
apenas duas discussões organizadas em comunidades virtuais que buscavam discutir projetos tramitando na Casa: a política de mudança do clima e o Estatuto da Juventude. Apesar de ter causado algum receio entre os deputados por se assemelhar a uma ferramenta de democracia direta (MITOZO et al, 2016), "outras comunidades foram paulatinamente criadas ao longo do segundo semestre de 2009 e do primeiro de 2010, entre elas as comunidades para discussão sobre a Amazônia, a política espacial e a regulação dos centros de inclusão digital (lan houses)" - (FARIA, 2012, p.185).

Passada essa fase inicial, o e-Democracia se firmou como um dos projetos mais relevantes de democracia digital no Brasil. Além de mantido pela casa legislativa, o eDemocracia foi gradativamente se tornando um laboratório de inovação nas áreas de participação, deliberação e transparência. Em um mesmo local, estavam disponíveis enquetes, bibliotecas de artigos sobre temas legislativos e bate-papos coletivos entre cidadãos e parlamentares, além de fóruns temáticos baseados em projetos de lei que visavam receber e fomentar opiniões e debates entre representantes e representados (a exemplo do explicitado acima no caso do Marco Civil da Internet). O e-Democracia também criou a ferramenta Wikilégis, que buscava uma construção colaborativa de textos legislativos. Logo, os seus participantes poderiam "elaborar sua própria versão do projeto de lei, além de promover alterações específicas no texto original do projeto de lei ou do texto substitutivo apresentado pelo deputado relator da matéria que está sob discussão" (FARIA, 2015, p. 187).

Segundo Faria et al (2016), nesses sete anos de existência, o e-Democracia consolidouse como instrumento de participação e transparência na Câmara dos Deputados. Com um número expressivo de participantes e de contribuições, proximidade do centro de tomadas de decisão e uma miríade de recursos para participação e possibilidades de discussões on-line, capacidade de inovação e sustentabilidade temporal, o e-Democracia pode ser considerado o projeto de democracia digital mais antigo e perene no caso brasileiro e, consequentemente, tem recebido vasta atenção acadêmica.

Note-se ainda que, em 2013, foi lançado o Laboratório Hacker, um laboratório de inovação democrática que busca criar e implementar diversas ferramentas e projetos de parlamento aberto na Câmara dos Deputados. A iniciativa pode ser descrita como uma evolução direta do e-Democracia, tornando-se um projeto maior que o envolve ${ }^{12}$. Consiste em um laboratório de inovação democrática diretamente associado ao poder Legislativo, visando à criação de ferramentas e/ou iniciativas inovadoras que rompam com os padrões burocráticos do processo legislativo tradicional. Além de assumir o e-Democracia e o Wikilegis, o LabHacker

12 Segundo seu site: "O LabHacker é um espaço para promover o desenvolvimento colaborativo de projetos inovadores em cidadania relacionados ao Poder Legislativo. Além de estimular o desenvolvimento de aplicações digitais que permitam a visualização mais intuitiva e simplificada das informações legislativas, o LabHacker promove atividades como maratonas hackers (hackathons), hackdays sobre temas inovadores, e oficinas de criação e discussão com especialistas, parlamentares, estudantes de universidades e escolas públicas, e crianças interessadas em tecnologia". http://labhackercd.net/about.html. Acesso em: 7 fev. 2018. 
criou recursos novos, como o "Retórica Parlamentar"13, que consiste em uma análise e visualização dos principais temas presentes nos pronunciamentos dos deputados brasileiros. A ferramenta organiza os discursos em bolhas temáticas, que permitem a fácil visualização dos deputados que mais tocam nos temas. Clicando no nome ou imagem de um deputado, é possível visualizar mais informações sobre ele.

Para a pesquisa aqui em foco foram identificadas as instituições e regiões dos autores, os tipos de trabalho e características da produção bibliográfica (considerando temas e subtemas analisados), as áreas do conhecimento envolvidas e as relações entre pesquisadores a partir da rede de citações e cocitações. A rede de citações também permitiu a análise de características que identificassem a formação de uma possível rede de autores e de conceitos, podendo vir a caracterizar possíveis escolas de pensamento em formação, identificáveis a partir da análise dos trabalhos sobre o e-Democracia.

O conteúdo analisado foram as palavras-chave e resumos dos trabalhos que tiveram o eDemocracia ou algum aspecto a ele diretamente relacionado como objeto central do estudo. Foi utilizado o software livre IRaMuTeQ ${ }^{14}$, desenvolvido pelo Laboratoire d'Études et de Recherches Appliquées en Sciences Sociales (LERASS) da Universidade de Toulouse. O IRaMuTeQ permite análises quantitativas diversas sobre corpora textuais ${ }^{15}$. Foi possível utilizar uma série de recursos do software para refinamento da pesquisa, como a contagem de palavras para o desenvolvimento de estatísticas textuais clássicas; a pesquisa por redes de conceitos; a visualização de nuvens de palavras; a análise de redes de coocorrência de termos; principais palavras citadas; análise de semelhanças e diferenças entre redes de interesse e a observação de proximidade - ou distância - entre termos.

Para gerar indicadores quantitativos iniciais foi realizada busca por trabalhos que contivessem qualquer menção ao e-Democracia, nos indexadores Google Scholar, Scielo e no Portal de Periódicos CAPES. Também foi realizada busca por trabalhos no banco de teses e dissertações da Capes. Como "e-Democracia" pode se referir tanto ao objeto quanto ao próprio campo de estudos, as buscas foram realizadas em união com outras palavras-chave que ajudassem a diferenciá-lo, como "Câmara dos Deputados", "projeto", "iniciativa" e "LabHacker", encontrando inicialmente um total de 73 trabalhos que mencionaram o projeto eDemocracia, incluindo trabalhos na língua inglesa.

Desse total foi excluído da pesquisa um conjunto de 11 produções que apenas mencionavam ou tangenciavam o e-Democracia, sem conter uma análise diretamente relacionada à iniciativa. Uma base de dados foi elaborada com os 62 estudos restantes.

\footnotetext{
${ }^{13} \mathrm{http} / / /$ retorica.labhackercd.net/. Acesso em: 7 fev. 2017.

${ }_{14}^{14}$ Disponível em: https://sourceforge.net/projects/iramuteq/. Acesso em 30 de julho de 2018.

15 Corpus textuais referem-se ao conjunto total de textos que estão sendo analisados numa pesquisa; no caso da presente pesquisa foram dois corpora: o conjunto de todas as keywords ou palavras-chave de cada trabalho e o conjunto de todos os abstracts.
} 
Posteriormente, uma série de metadados sobre cada estudo foi catalogada manualmente, entre eles: autoras e autores e respectivas instituições de origem; áreas de concentração; tipos de trabalho, tais como artigos para periódicos, capítulos de livros, teses, dissertações e monografias; ano de publicação da produção; conteúdo das palavras-chave e dos resumos de cada documento.

Posteriormente, a atenção voltou-se ao conjunto de autoras e autores que apareciam como referências citadas em cada um dos 62 estudos analisados. Foi produzida uma base de dados contendo todos os nomes citados por cada estudo, contabilizando também o número de vezes que cada nome foi citado em cada estudo. A partir disso, usando o software livre, gratuito e de código aberto R (R CORE TEAM, 2017), foram construídos indicadores quantitativos sobre as citações feitas pelos estudos, permitindo identificar as pessoas ou entidades mais citadas no campo.

Foi produzida, ainda, uma rede de cocitações entre os nomes citados. De acordo com White e Griffith (1981), a rede de cocitações é formada quando consideramos cada autor como um elemento (ponto ou nó) da rede e cada estudo em que dois autores aparecem juntos na lista de referências como uma relação (linha ou ligação) da rede. Ou seja, dois autores quaisquer são ligados entre si caso sejam citados pelo mesmo estudo. Com isso foi possível realizar análises com base em alguns indicadores, tais como o número de cocitações entre autores, identificando autores de maior influência no campo e a proximidade (ou distância) relativa entre os autores ao serem articulados pelos 62 estudos analisados.

Tendo em vista o fato de que as redes de cocitação costumam revelar agrupamentos mais densos em seu interior, isto é, grupos de referências que são articulados com mais frequência pelos estudos analisados, também foram detectados esses agrupamentos. Para tanto, utilizamos o algoritmo de detecção de comunidades de autovetores líderes, desenvolvido por Newman (2006), que se mostrou robusto em testes exploratórios.

\section{Resultados}

Os resultados de cada pesquisa são apresentados e discutidos a seguir.

\subsection{Tipos de estudo e produção}

Foi interesse da pesquisa em tela verificar se a produção acerca do e-democracia era predominantemente científica ou não. A figura a seguir ilustra o cenário analisado. 
Gráfico 1: Tipos de produção acadêmica sobre o e-Democracia ${ }^{16}$

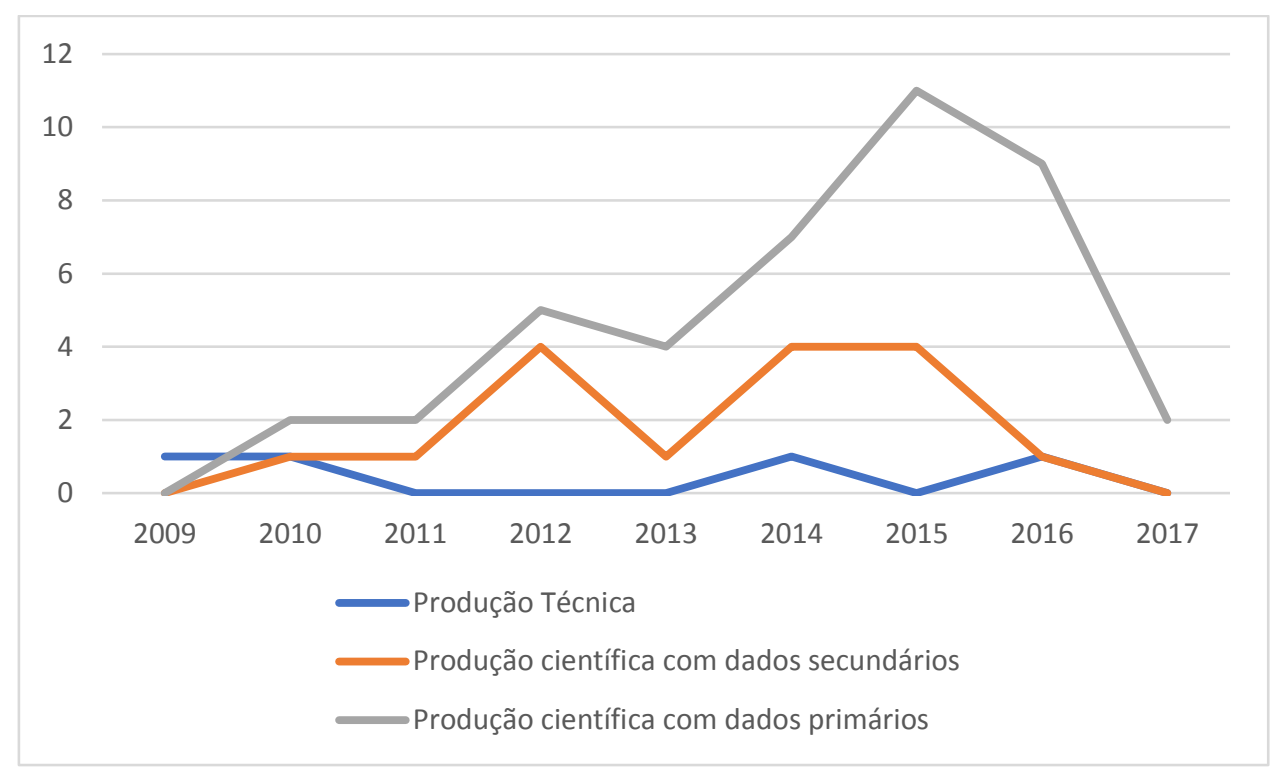

Fonte: Elaboração própria, 2018.

Pode-se dividir a história da produção bibliográfica do e-Democracia em três etapas. A primeira, desde o seu início, em 2009, até 2011. Essa fase caracteriza-se pela produção de trabalhos com poucos dados empíricos sobre a plataforma e, talvez por isso, há predominância de produções técnicas. À época, havia mesmo poucas informações disponibilizadas pela plataforma, dada a sua pouca maturidade e tempo de existência. Foram, no total, duas produções técnicas, duas produções científicas com dados secundários e quatro com dados primários.

De 2012 a 2014, a produção torna-se mais embasada em pesquisas e a maioria passa a ser de produção científica com dados primários ou secundários - do total de vinte e seis trabalhos dessa fase, vinte e cinco apresentam tais características. Os trabalhos apresentam pressupostos teóricos e conceitos desenvolvidos para compreensão do objeto de pesquisa a ser analisado; baseiam suas conclusões em pesquisas novas, originais, com dados primários, ou em dados secundários, frutos de pesquisas acadêmicas e governamentais já realizadas. Maior refinamento teórico e empírico dos trabalhos é observado. O tempo de existência da iniciativa colabora para esse cenário, já com número suficiente de dados disponibilizados para coleta, análise de dados e realização de pesquisas.

\footnotetext{
16 Para ser considerado como produção científica foram observados os seguintes critérios: apresenta pressupostos teóricos; usa conceitos para compreensão do objeto de pesquisa a ser analisado; baseia suas conclusões em pesquisas novas, originais ou em pesquisas acadêmicas e governamentais já realizadas. Ainda a respeito das produções científicas, duas distinções foram aplicadas: a. produção científica com base em pesquisas originais - revela o potencial da iniciativa de fornecer dados primários para a realização de novas pesquisas; b. produção científica com base em pesquisas já realizadas - revela a consolidação do e-Democracia como objeto de pesquisa do campo de democracia digital, sendo aqui classificados os trabalhos que trabalharam com dados secundários. Foram considerados como produções técnicas aqueles trabalhos com inexistência de referencial teórico, de metodologia ou de evidência empírica das constatações e análises apresentadas (whitepaper, alguns papers para congressos e capítulos de livros).
} 
Após três anos de atividades, a plataforma passa a oferecer dados e informações relevantes para análises, como o histórico das discussões a respeito de projetos de lei nas comunidades legislativas e o próprio trâmite de projetos de lei, sendo possível analisar não só o caminho do projeto até sua aprovação, mas também as controvérsias que, muitas vezes, impediram-no de prosseguir e ser sancionado. Nessa segunda fase, portanto, a maioria da produção é de trabalhos que apresentam resultados de pesquisas originais com rigor teóricometodológico e avaliação por pares.

A terceira fase tem início em 2015 e vai até 2017, fase em que foram identificadas uma produção técnica, cinco pesquisas com dados secundários e vinte duas (ou $78 \%$ do total) elaboradas com base em dados primários. A maioria da produção relacionada ao e-Democracia, portanto, é científica, sendo uma grande parte dela elaborada sob a forma de artigos para periódicos, capítulos de livro e trabalhos de conclusão de cursos de graduação e pós-graduação. Interessante observar que o número de produção científica original continuou a aumentar ao longo do tempo apesar da quantidade geral de trabalhos produzidos ter diminuído.

\subsection{Origem regional e institucional}

Em um primeiro momento foram analisadas características formais básicas associadas aos autores responsáveis pelos artigos e estudos identificados, como sua origem institucional e regional. Os autores e autoras são, em sua grande maioria, da região centro-oeste (48\%), o que pode ser explicado pelo fato de a iniciativa ter sido desenvolvida na capital do país e sua equipe de coordenação ser fortemente ligada a atividades de ensino e pesquisa desenvolvidas na Universidade de Brasília (UnB). Essa proximidade e curiosidade sobre a iniciativa tendem a gerar projetos e trabalhos conjuntos.

Além disso, autores do Centro de Formação, Treinamento e Aperfeiçoamento (CEFOR) da Câmara dos Deputados representam um grande grupo de interessados em analisar o eDemocracia. A região sul também apresenta um número considerável de autores (14 de 61, ou $23 \%$ do total), sendo aqueles da região sudeste (13 ou $21 \%$ do total) o terceiro grupo que possui claro interesse pelo objeto de pesquisa em questão ${ }^{17}$. Interessante ressaltar que, assim como nos resultados da pesquisa de Sampaio et al (2016) sobre os estudos de Internet e Política, as universidades tradicionais do país também não surgem como as principais produtoras de conhecimento a respeito do e-Democracia, como destacado no gráfico 2 a seguir.

\footnotetext{
${ }^{17}$ Foram identificados dois autores da região nordeste (ou 3\% do total), nenhum autor da região norte e 3 autores (ou $5 \%$ do total) de outros países que não o Brasil.
} 
Gráfico 2: Número de autores por instituição

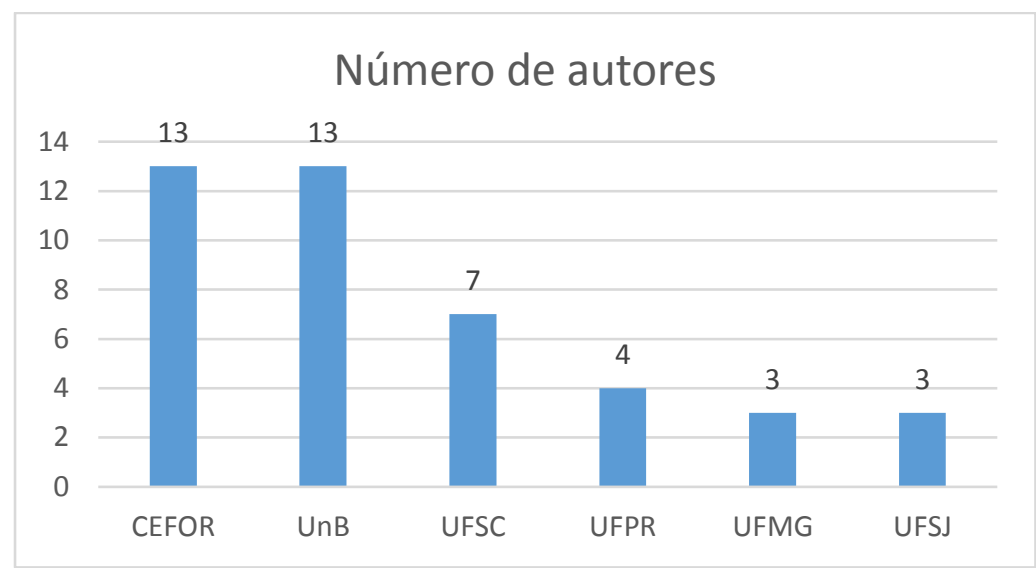

Fonte: Elaboração própria, 2018.

Ainda assim, cidades da região sudeste e sul são destaque, com instituições e pesquisadores interessados no tema. Essa constatação é observada tanto na pesquisa prévia mencionada quanto na presente pesquisa. Enquanto a Universidade Federal da Bahia aparece como a mais importante no campo de produção de conhecimento sobre Internet e Política no campo da Comunicação, o cenário aqui analisado revela-se um pouco distinto, com preponderância de estudos na região Centro-Oeste, especialmente em Brasília.

Foram identificadas 24 organizações que possuem algum trabalho diretamente relacionado ao e-Democracia. Vale ressaltar que todos os trabalhos foram desenvolvidos em universidades e instituições de ensino e pesquisa. Dezessete delas, ou 71\% do total, possuem apenas um autor e uma produção. Apenas 30,65\% dos estudos apresentam trabalhos em coautoria. Sete instituições, das 24, apresentam mais de uma produção. A organização que mais possui trabalhos na área é o Centro de Formação, Treinamento e Aperfeiçoamento da Câmara dos Deputados, em Brasília, aonde vários profissionais da Câmara realizam cursos de pósgraduação, entre eles profissionais que atuam no próprio e-Democracia. Das 24 instituições, duas universidades norte-americanas (University of Hull \& Harvard Kennedy School) e uma portuguesa (Universidade do Minho) foram identificadas.

Esses dados indicam algo esperado, que ao nos centrarmos em um objeto mais específico de democracia digital, novos atores institucionais podem ganhar relevância e importância em relação ao campo geral de estudos. Trata-se claramente do caso da UnB, que geralmente não está entre as 5 universidades mais relevantes no que tange a estudos sobre Internet e Política (I\&P), mas que se torna uma das principais produtoras de conhecimento a respeito do e-Democracia. Em especial, diferentes cursos da UnB apresentaram pesquisas sobre o projeto, nomeadamente Comunicação Social, Ciência Política e Políticas Públicas. 


\section{3 Áreas do conhecimento}

O subcampo de democracia digital tende a ser multidisciplinar, o que parece reproduzirse nas análises sobre o e-Democracia. Em 62 trabalhos produzidos sobre a iniciativa ao longo de nove anos, 19 áreas do conhecimento estão envolvidas. Entretanto, apenas quatro destacam-se pela participação mais significativa em termos numéricos. A ciência política foi responsável por 26,5\% da produção, enquanto a área de Comunicação foi responsável por 12,5\% dos trabalhos. A terceira área de concentração mais produtiva foi a do Campo de Públicas ${ }^{18}$ (11\%) e, em seguida, a do Direito $(9,5 \%)$. Ao reunir as quatro áreas citadas, chega-se a 59,5\% da produção.

$\mathrm{Na}$ pesquisa realizada a respeito do campo de Internet e Política (I\&P) no Brasil (SAMPAIO; BRAGATTO; NICOLÁS, 2016), cerca de 60\% da produção tinha como origem as áreas de Comunicação $(45,6 \%)$ e Ciência Política (13,9\%). Apesar da multidisciplinariedade reconhecida, esses dados sugerem que o campo de democracia digital começa a ter algumas áreas do conhecimento que passam a configurar-se como centrais para a sua produção acadêmica.

Ao investigar a área de conhecimento na qual foram elaboradas as teses de doutorado, o mesmo cenário é observado. Foram três teses desenvolvidas, sendo uma da Ciência Política da UERJ, uma da Comunicação da PUC/RS e a terceira do Campo de Públicas da Universidade de Brasília (UnB). As dez dissertações de mestrado identificadas também confirmam a tendência às mesmas áreas do conhecimento concentrarem a produção. Do total, três foram desenvolvidas na Ciência Política, duas na Comunicação, uma no Campo de Públicas, uma no Direito, uma na Administração, uma na Ciência da Informação e, por fim, uma na área de Engenharia ${ }^{19}$. As quatro áreas centrais reaparecem - Comunicação, Ciência Política, Direito e o Campo de Públicas.

Dentro do esperado, ao especializar o estudo sobre um objeto, o subcampo começa a apresentar diferenças em relação à área mais ampla de internet e política. Não obstante, é válido destacar que áreas que são pouco vistas no campo ampliado de I\&P, ganham força nos estudos sobre o e-Democracia, como é o caso do Direito e de Políticas Públicas, algo também visto na emergência de outras instituições em destaque, como é o caso da UnB. Isso vai ao encontro dos dados de Sampaio e colegas (2016) que demonstram que a Comunicação, geralmente, tem mais

\footnotetext{
${ }^{18}$ Segundo Pires et al., "Campo de Públicas é uma expressão utilizada por professores, pesquisadores, estudantes, egressos-profissionais e dirigentes de cursos de Administração Pública, Gestão de Políticas Públicas, Gestão Pública, Gestão Social e Políticas Públicas, de universidades brasileiras, para designar, essencialmente, um campo multidisciplinar de ensino, pesquisa e fazeres tecnopolíticos, no âmbito das Ciências Sociais Aplicadas e das Ciências Humanas, que se volta para assuntos, temas, problemas e questões de interesse público, de bem-estar coletivo e de políticas públicas inclusivas, em uma renovada perspectiva republicana ao encarar as ações governamentais, dos movimentos da sociedade civil organizada e das interações entre governo e sociedade, na busca do desenvolvimento socioeconômico sustentável, em contexto de aprofundamento da democracia" (Pires et al., 2014, p. 112). Observa-se, portanto, que as produções acadêmicas do campo de públicas e seus cursos estão distribuídos por diversas áreas e subáreas do conhecimento, como Ciência Política, Administração, Sociologia, Economia e Demografia.

${ }^{19}$ A dissertação foi desenvolvida em uma pós-graduação do Centro Tecnológico da Universidade Federal de Santa Catarina Engenharia/Gestão/Tecnologia, uma área específica de avaliação da Capes.
} 
interesse em objetos da vertente social, enquanto a Ciência Política se debruça prioritariamente sobre objetos institucionais, como é o caso do e-Democracia. Porém, para além disso, os dados evidenciam que há outras áreas interessadas em democracia digital que estão mais distantes da comunicação política, como é o caso do Direito e dos diferentes cursos do campo de públicas, que ganham destaque nos estudos sobre o e-democracia.

Gráfico 3: Quantidade de Autores por área do conhecimento

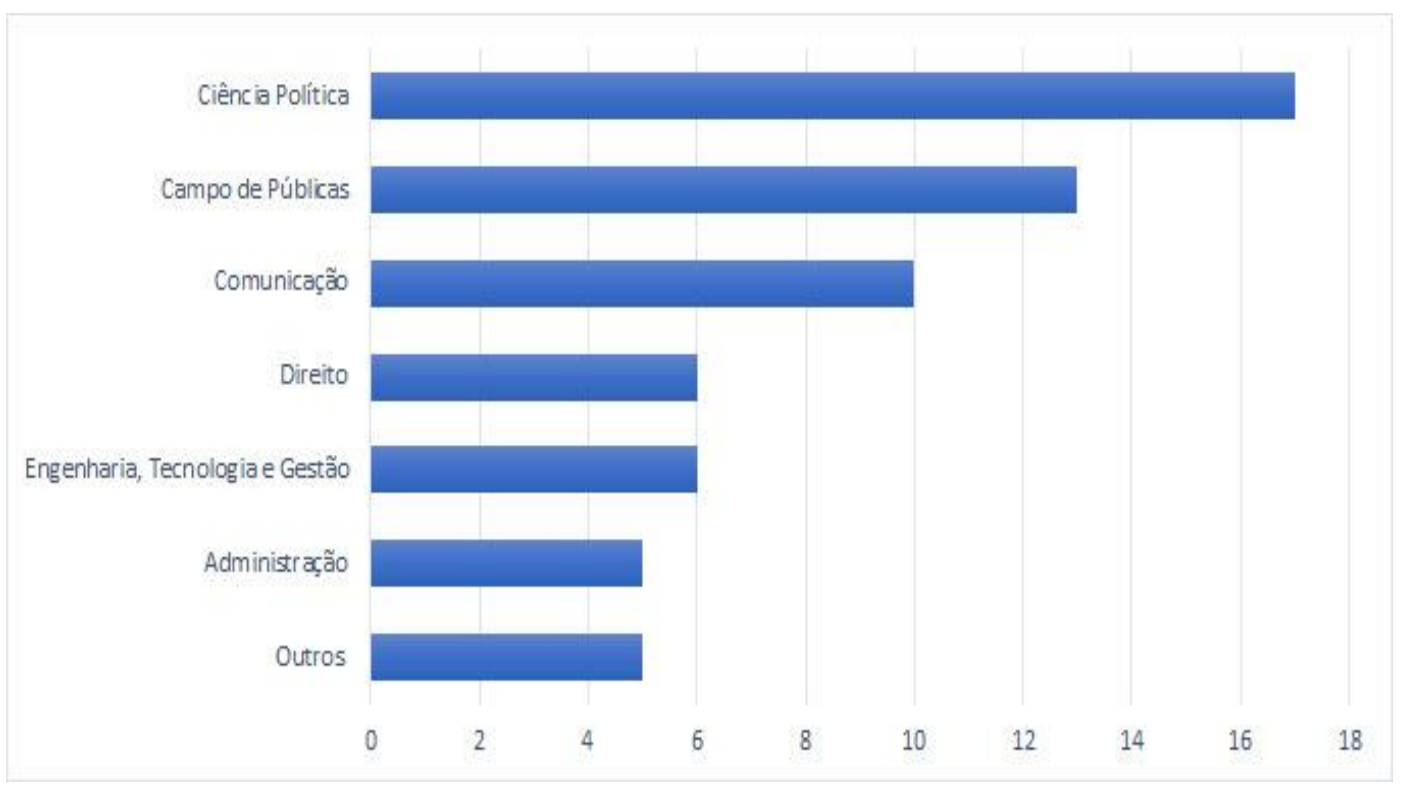

Fonte: Elaboração própria, 2018.

\subsection{Temas e termos}

Em cada uma das etapas identificadas, observa-se a predominância de determinados temas e subtemas. Especialmente na segunda fase de produção sobre o e-Democracia, existe uma tendência à discussão de temas específicos, com discussões mais aprofundadas.

Tais temas incluem crowdsourcing - ou práticas dedicadas a angariar recursos materiais e imateriais de forma colaborativa para a construção de políticas públicas e outras ações governamentais; crowdlaw, ou a produção colaborativa de leis; análise dos processos que levam (ou não) à participação cidadã; limitações quanto às possibilidades de as ferramentas para participação política digital aprimorarem a democracia; desenvolvimento de taxonomia para compreensão dos mecanismos de funcionamento das iniciativas com base em indicadores que analisam estrutura de governança, cultura organizacional e sustentabilidade (FREITAS; EWERTON, 2018). Como tendência geral do campo de democracia digital, temas como controle social, transparência, inovação democrática também começam a ser tratados nos trabalhos analisados.

A análise com o IRaMuTeQ permitiu reunir as palavras mais frequentes nos resumos analisados. A palavra "participação" é a que mais aparece (92 vezes), sendo, portanto, central 
para a maioria dos trabalhos analisados. O termo pode aparecer sozinho ou combinado a outros, desenvolvendo reflexões acerca da democracia participativa, da participação cidadã, participação política digital, participação política, e-participação e tantas outras possibilidades que revelam conceitos caros ao campo de democracia digital. Outros termos bastante frequentes são "política" (55 vezes), "cidadão" (54 vezes), "e-democracia” (50 vezes) e "informação" (47 vezes). Tais termos estão presentes em praticamente toda a produção analisada, como revela a figura a seguir.

Gráfico 1: Rede de coocorrência de palavras extraídas dos abstracts

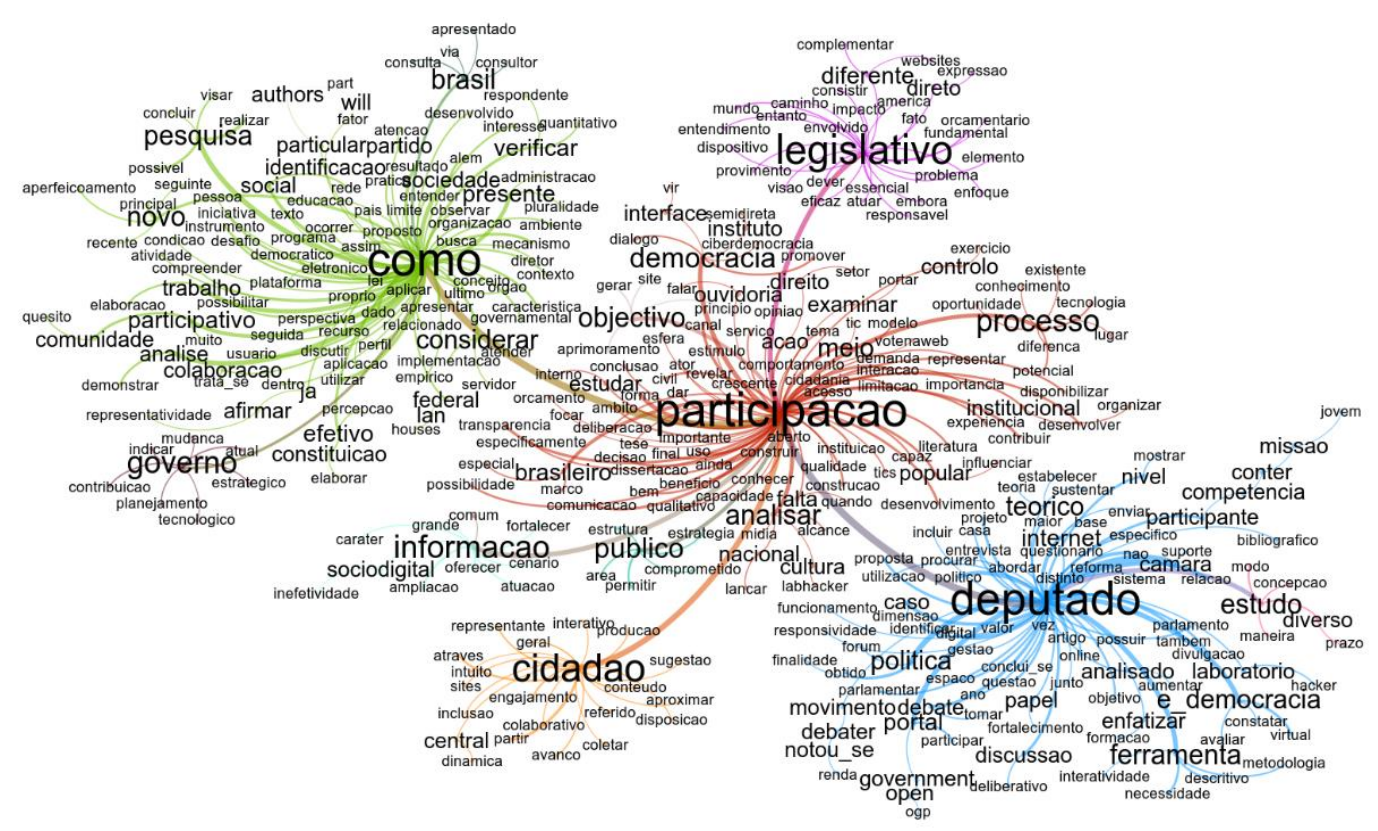

Fonte: Elaboração própria, 2018.

Como pode ser observado na figura 05, quatro grupos principais de palavras foram encontrados. Todos eles possuem conexão significativa com o grupo central, aquele em que os termos "participação", "informação", "cidadão" surgem de forma mais frequente. "Participação", em especial, aparece como o grande tema central, unindo outros clusters como “democracia", "processo", público", "legislativo", “cidadão" e "deputado", evidenciando que a literatura tendeu a tratar o e-Democracia, especialmente, como uma plataforma que permite a participação do cidadão em interação com seus representantes políticos.

Os termos "como", "pesquisa" e "analisar" também foram encontrados com uma frequência considerável, revelando a característica de grande parte dos trabalhos ser referenciada em pesquisas. Nesse sentido, a aparição do primeiro termo demonstra a existência de diferentes análises, por exemplo, a respeito de "como foi feita determinada pesquisa", "como foram descobertos e analisados os resultados", "como a iniciativa aprimora a democracia", "como a participação cidadã acontece" etc. Entretanto, palavras que fizessem referências a 
métodos ou técnicas de pesquisa não chegaram a formar um cluster, o que pode ser um indicativo de não serem valorizadas no resumo.

Interessante notar que por mais que o e-Democracia seja predominantemente baseado em ferramentas dialógicas, o termo "deliberação" e seus similares (i.e. diálogo, debate, discussão etc.) não chegam a formar um cluster de destaque. Ademais, por mais que esteja entre seus objetivos, o mesmo acontece com transparência e termos/conceitos próximos, como "parlamento aberto", "accountability" ou mesmo "publicidade" 20 . Por último, também importa destacar que a chave-analítica principal de nosso artigo parece ser pouco presente no subcampo estudado, ou ainda, democracia digital e similares também não formam um cluster entre as palavras de resumo. Em todos esses casos, encontramos dados distintos nas palavras-chave, como destacados abaixo.

A rede de co-ocorrência de palavras produzida com as palavras-chave dos trabalhos analisados evidencia similaridades com as anteriores e outras diferenças notáveis. O termo "democracia" é o mais frequente, aparecendo 23 vezes, acompanhado das palavras “participação" (20 vezes), "política” (19 vezes) e "e-democracia” (13 vezes).

Gráfico 2: Rede de coocorrência de palavras-chave

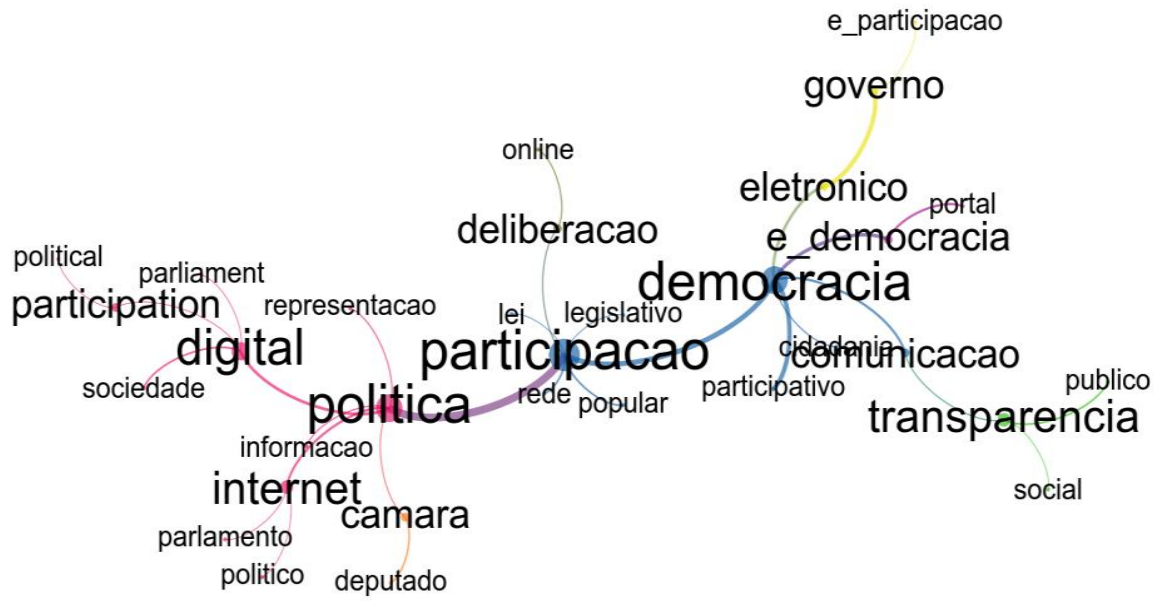

Fonte: Elaboração própria, 2018.

Como no caso dos resumos, é notório que o termo "participação" continua sendo a palavra-chave central, unindo os diferentes campos de estudo. Porém, aqui, as subáreas da internet e política ficam claramente representadas. Muito próximo à ideia de participação, teríamos o subcampo da "deliberação online" e, logo em seguida, da "democracia digital", que é uma ponte tanto para os estudiosos de "governo eletrônico" quanto para aqueles de comunicação e transparência. No outro lado do quadrante, estariam os estudos mais legislativos,

\footnotetext{
${ }^{20}$ Não obstante, o cluster em torno do termo "informação" pode, eventualmente, estar mais conectado aos trabalhos de transparência. Há, todavia, a possibilidade que a informação aqui esteja sendo pensada como algo importante à uma participação mais qualificada e efetiva.
} 
focando, notadamente, em parlamento digital (online), informação e sociedade digital. Notadamente, repete-se a situação de não aparecem termos ligados ao uso de métodos ou técnicas de pesquisa, o que reforça o achado de se tratar de algo pouco abordado por este subcampo de pesquisa.

Como pode ser observado, várias palavras identificadas coincidem com as abordagens conceituais recorrentes encontradas na pesquisa de Sampaio et al (2016) e, também, na investigação de Gomes (2016).

\subsection{Rede de citações e cocitações}

Os autores mais citados ${ }^{21}$ nos trabalhos analisados foram Jamil Marques, Cristiano Faria, Wilson Gomes e Jürgen Habermas. Ao analisar a atuação de cada um deles, percebe-se a distribuição relativamente uniforme entre algumas principais áreas do conhecimento que desenvolvem trabalhos sobre o e-Democracia: Comunicação, Ciência Política, Direito e a área bastante multidisciplinar do campo de públicas, que abarca políticas públicas, gestão de políticas públicas, gestão pública, dentre outras. Ciências sociais e filosofia também aparecem como áreas relevantes.

Ao contabilizar todas as cocitações identificadas, obtivemos uma rede com 1.963 autores e 175.418 relações de cocitação entre eles. Para melhor trabalhar e visualizar essa quantidade de dados, identificamos subredes e filtramos os nós mais centrais como um critério de corte. Foram identificadas treze subredes de cocitação na rede ampliada de autores interessados pelo e-Democracia, cada qual com seu líder. As três subredes com maior número de cocitações são aquelas lideradas por Cristiano Faria, Manuel Castells e Joseph Schumpeter. Significa que esses líderes são os nós mais centrais da rede quando considerado o seu grau. O líder da comunidade é o nó com maior grau de interações daquela comunidade. Significa que Schumpeter ${ }^{22}$, por exemplo, pode ter sido citado em um documento que citou uma grande quantidade de autores (e isso conferiu a ele um grau de centralidade significativo no interior da rede); contudo, o autor não necessariamente aparece numa quantidade significativa de trabalhos, pondo em xeque sua centralidade.

Por isso foi utilizado, também, outro critério de corte: o da medida de centralidade das ligações de peso 9 ou superior. Nesse caso, cenário distinto é observado. Aqui, não basta um autor ter muitas cocitações para aparecer na rede, mas ele precisa ser cocitado em conjunto com um outro autor pelo menos 9 vezes, demonstrando sua importância para a rede e seu reconhecimento entre os pares. A figura a seguir demonstra a rede encontrada a partir desse

\footnotetext{
${ }^{21}$ Os autores mais citados aqui considerados são aqueles que obtiveram mais de $1,1 \%$ do total de referências ou mais de 50 citações.

${ }^{22}$ Curioso notar que Schumpeter é reconhecido como sendo um autor elitista, notadamente contrário à participação dos cidadãos no cotidiano político, excetuando-se as eleições (Schumpeter, 1942). Portanto, o mais provável é que suas teorias sejam acionadas para serem rebatidas e criticadas com o exemplo do e-Democracia.
} 
critério, revelando os nós (autores e autoras) centrais da rede.

Gráfico 3: Rede de cocitações circular

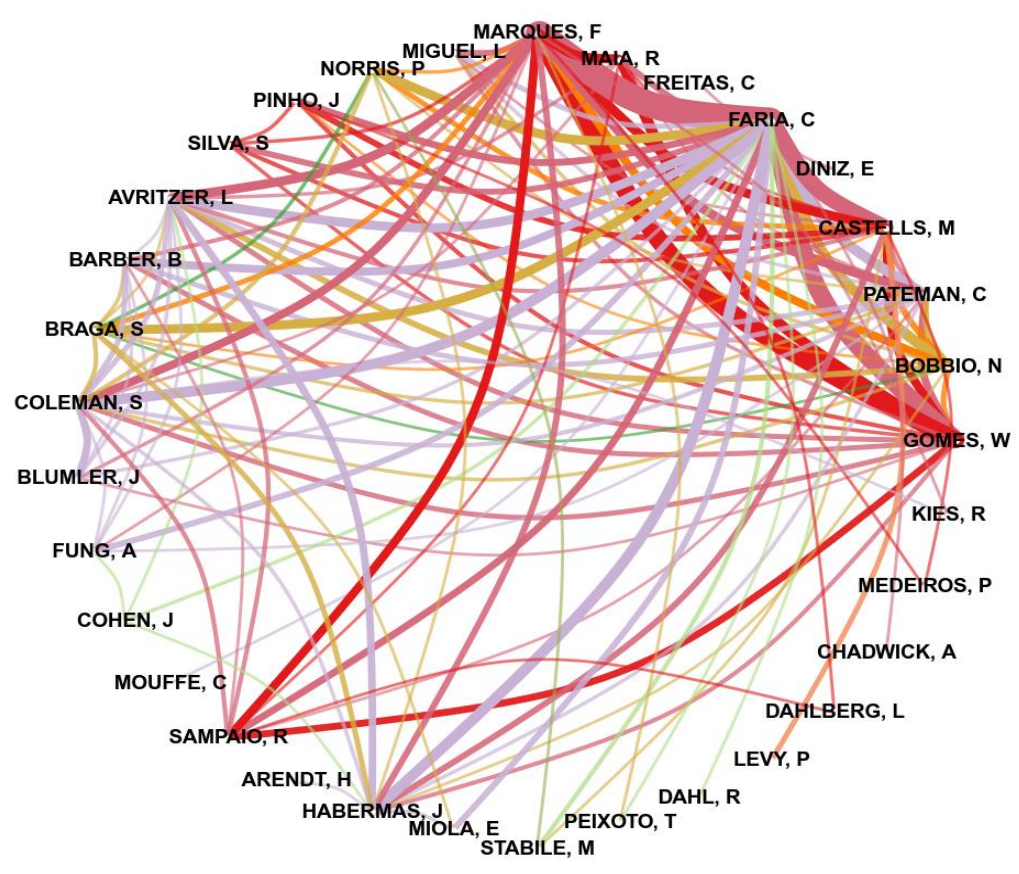

Fonte: Elaboração própria, 2018.

A figura a seguir apresenta outra forma de visualização da rede com suas subredes, destacando, ao centro, aqueles autores e autoras mais citados. Desta vez, a posição de cada elemento da rede foi determinada por um algoritmo de forças, descrito por Fruchterman e Reingold (1991), o que significa que a distância entre os elementos na figura reflete sua proximidade na rede.

Gráfico 4: Rede de cocitações de acordo com a força de cada nó

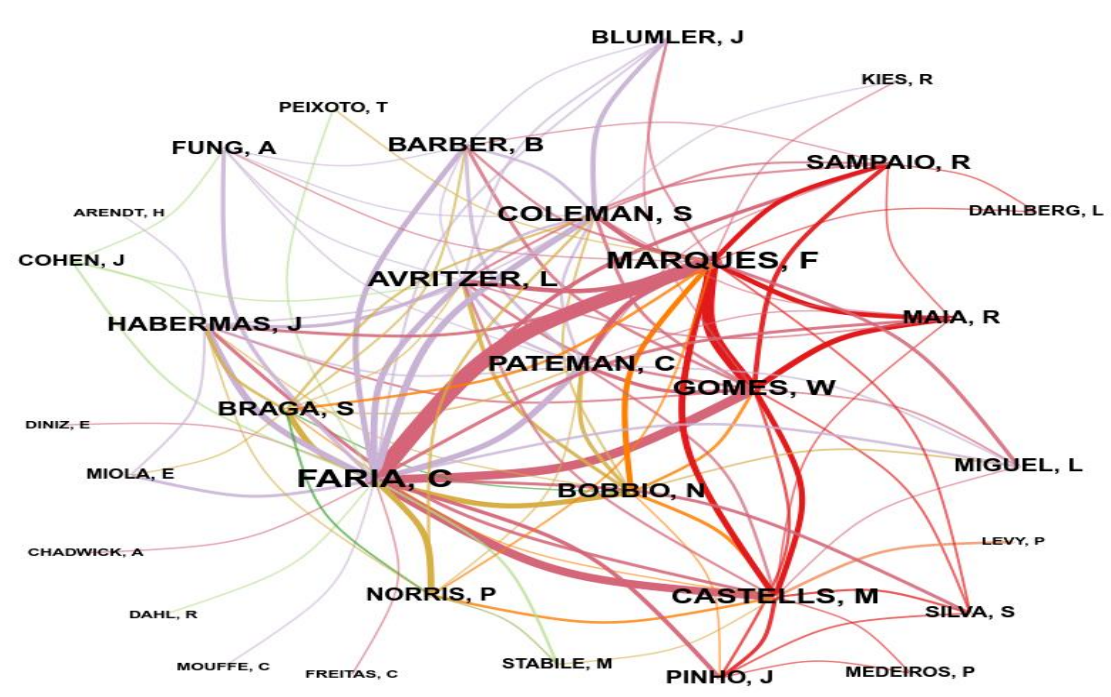

Fonte: Elaboração própria, 2018. 
Na figura 9, observa-se a centralidade de cada autor ou autora de forma mais clara. Aqueles nós associados ou ligados a partir de linhas mais espessas do que as demais aparecendo no centro da imagem - são aqueles mais citados em um número maior de trabalhos e de forma associada a mais outros nós, formando uma rede densa de produção de conhecimento.

Essa rede de cocitações também evidencia a centralidade de autores e teorias da internet e política. Interessante observar que, dos quatro autores mais centrais (Wilson Gomes, Jamil Marques, Cristiano Faria e Manuel Castells), os três primeiros pertencem ao Instituto Nacional de Ciência e Tecnologia em Democracia Digital (INCT.DD), caracterizando o Instituto como central na rede estudada ${ }^{23}$. Esse fato também foi apontado por Sampaio et al (2016), ao analisar a rede de produtores de conhecimento do campo de Internet e Política. Para além disso, fica claro que a grande maioria dos autores presentes em nosso estudo estão, de fato, no grande campo da democracia digital ${ }^{24}$. No entanto, percebe-se que poucos autores da área de governo eletrônico são acionados frequentemente nas cocitações, só ficando evidentes Andrew Chadwick, José Antônio Pinho e Eduardo Diniz.

Por sua vez, é notável como autores da participação política presencial, como Carole Pateman, Benjamim Barber, Leonardo Avritzer e, em menor medida, Archon Fung são bastante acionados pela área. Avritzer, Jürgen Habermas, Rousiley Maia, Wilson Gomes, Stephen Coleman, Rafael Sampaio, Jamil Marques, Edna Miola, Raphael Kies e Lincoln Dahlberg representariam os autores que utilizam conceitos mais próximos aos da democracia deliberativa (e.g. deliberação pública, esfera pública), incluindo estudos sobre deliberação em ambientes online. Por sua vez, diversos pensadores da teoria democrática estão presentes, como Norberto Bobbio, Chantal Mouffe, Robert Dahl, Luis Felipe Miguel e Hannah Arendt.

Por sua vez, fica perceptível que o mesmo não ocorre com autores de subáreas da democracia digital e mesmo da teoria democrática, notadamente da transparência digital e mesmo dos recentes avanços na área de governo aberto e dados abertos. Enquanto há autores que figuram nessas linhas (Jamil Marques, Sivaldo Silva, Tiago Peixoto e Wilson Gomes), ficou evidentes que eles nem formam clusters fortes (i.e. são cocitados com frequência) nem são frequentemente usados na temática da transparência. Corroborando dados anteriores, mesmo com o surgimento do Laboratório Hacker e mesmo com a criação de ferramentas voltadas para ampliação da transparência pública da Câmara, o e-Democracia continua sendo prioritariamente analisado enquanto um projeto de e-participação política (que pode incluir a análise através das conversações online existentes em seu interior).

\footnotetext{
${ }^{23}$ É ainda o caso de Rafael Sampaio, Christiana Freitas, Sérgio Braga, Edna Miola, Sivaldo Silva, além dos participantes de centros internacionais, como Stephen Coleman, Tiago Peixoto e Raphael Kiss. Para mais sobre o INCT.DD, ver https://inctdd.org/. Acesso em 09 mar. 2020.

${ }^{24}$ Jamil Marques, Wilson Gomes, Rafael Sampaio, Stephen Coleman, Jay Blumler, Sivaldo Silva, Lincoln Dahlberg, Edna Miola, Christiana Freitas, Pierre Lévy (i.e. Ciberdemocracia).
} 
Por conseguinte, é pertinente destacar que poucos autores, efetivamente, da literatura de parlamentos online (e-parlamentos, parlamentos 2.0, parlamentos abertos etc.) foram vistos na literatura. Apesar da posição central de Cristiano Faria e Stephen Coleman, poucos autores sobre o tema aparecem em nossas redes de cocitação ${ }^{25}$, deixando de fora, portanto, alguns dos principais autores da área ${ }^{26}$. Apesar de ser apenas um dado isolado, isso pode ser um indicativo de uma falta de especialização na área.

Destaque-se, ainda, que tanto nas palavras dos resumos quanto nas palavras-chave não há termos ligados a métodos ou técnicas de pesquisa, o que pode evidenciar uma fragilidade da pesquisa da área, algo que poderia ser verificado em futuras pesquisas.

\section{Conclusão}

Foram elaboradas e aplicadas categorias de análise para a avaliação da rede de pesquisadores interessados na iniciativa e-Democracia, rede esta que pertence ao campo mais abrangente de Internet e Política. Foi realizado mapeamento para análise dos autores e autoras interessados na iniciativa, suas origens institucionais, regionais, áreas de conhecimento e os tipos de trabalho mais encontrados. As análises de temas e termos relevantes também foram fundamentais para a compreensão mais acurada do subcampo de estudos em questão. Por sua vez, as redes de citação e cocitação entre autores foram importantes ferramentas de análise, permitindo a descoberta de tendências, como o destaque de alguns teóricos - e de algumas instituições centrais para o campo de Internet e Política no Brasil, como o Instituto Nacional de Ciência e Tecnologia em Democracia Digital (INCT.DD).

Nossos resultados indicam duas direções relativamente opostas. Por um lado, as instituições e áreas, de concentração dos estudos sobre o e-Democracia são significativamente diferentes daquelas vistas na área de I\&P, inclusive permitindo a entrada de novos atores, como é o caso da UnB, como instituição, e das áreas de Direito e do Campo de Públicas. Isso evidencia que, ao focar especificamente em determinados temas e/ou objetos do campo de democracia digital, há espaços que podem ser ocupados por outros atores e centros de pesquisa.

Por outro lado, ao verificarmos as coocorrências de palavras-chave e de cocitações, vemos que os estudos sobre o e-Democracia são bastante similares aos apresentados pela área de I\&P e, consequentemente, de comunicação e política, com destaque para aqueles atuantes da democracia digital. Isso tende a indicar que ainda há espaço para outros tipos de estudos e aparatos conceituais na avaliação do objeto em questão, como seria o caso de áreas correlatas, a exemplo do governo eletrônico, transparência digital e governo aberto. Notadamente, na análise das cocitações, alguns dos principais autores de parlamentos online não são acionados, o que

\footnotetext{
${ }^{25}$ Aparecem ainda: Sérgio Braga e Jamil Marques.

${ }^{26}$ A exemplo de: Andre Rehbein-Sathler, Antonio Teixeira de Barros, Cristiane Bernardes, Cristina Leston-Bandeira, Darren Lilleker, Franz Foltz, Malena Rehbein-Sathler, Paul Ferber, Philip Norton, Rachel Gibson, Rudy Pugliese, Thomas Zittel, Wainer Lusoli e tantos outros.
} 
poderia indicar uma falta de especialização nos temas e questões mais específicos de uma ferramenta de democracia digital ligado ao parlamento brasileiro.

As categorias analíticas mobilizadas podem vir a ser usadas como aparato metodológico para análise de outras ferramentas de e-participação, avaliando sua penetrabilidade nas várias áreas do conhecimento, nas diversas regiões do país e do mundo, bem como sua consolidação ou não - como instrumento para expansão de práticas democráticas participativas.

Estudos futuros também podem realizar análises das citações e cocitações entre autores, verificando as citações dos autores que surgiram, por exemplo, como líderes das comunidades (ou subredes) encontradas. Seriam aqueles citados colegas de uma mesma área de conhecimento? Com isso seria possível verificar - ou não - possível tendência à concentração da produção em áreas específicas, levando à reprodução de estrutura disciplinar tradicional no campo de produção de conhecimento científico no Brasil.

\section{Referências}

CURTINOVI, J.; PARMEGGIANI, B. Investigações sobre democracia digital no Brasil: Um mapeamento da produção acadêmica até 2013. Revista Comunicando, v. 4, p. 99-116, 2015.

FARIA, C. F. S. D. O Parlamento aberto na era da internet: pode o povo colaborar com o Legislativo na elaboração das leis? Brasília: Edições Câmara, 2012.

FARIA, C.; REHBEIN, M.; SATHLER, A. Netizen em ação: hackeando o parlamento a partir de dentro 3. In: PEREIRA, Silvaldo; BRAGATTO, Rachel; SAMPAIO, Rafael. (org.). Democracia digital, comunicação política e redes. Folio Digital: Rio de Janeiro, 2016.

FREITAS, C. S.; FIUZA, F.; QUEIROZ, F. Os desafios ao desenvolvimento de um ambiente para participação política digital: o caso de uma comunidade virtual legislativa do projeto EDemocracia no Brasil. Organizações \& Sociedade, v. 22, p. 639-657, 2015.

FREITAS, C. S.; EWERTON, I. Networks for Cyberactivism and their Implications for Policymaking in Brazil. In: ALCAIDE-MUÑOZ, L; ALCARAZ-QUILES, F. J. (ed.). Optimizing E-Participation Initiatives through Social Media. Pennsylvania: IGI Global Disseminator of Knowledge, 2018.

FRUCHTERMAN, Thomas M. J.; REINGOLD, Edward M. Graph Drawing by Force-Directed Placement. Software - Practice \& Experience, v. 21, n. 11, 1991, pp. 1129-1164.

GOMES, Wilson. 20 Anos de política, Estado e democracia digitais: uma cartografia do campo. In: SILVA, S.P.; BRAGATTO, R.C.; SAMPAIO, R.C. (org.). Democracia digital, comunicação política e redes: teoria e prática. Rio de Janeiro: Editora Letra \& Imagem, 2016. p. 25-45.

MITOZO, I. B.; MARQUES, F. P. J.; MONT'ALVERNE; C. Como se configura a comunicação online entre representantes e representados no brasil? Um estudo sobre as ferramentas digitais da Câmara dos Deputados. Contracampo, v. 35, n. 2, 2016.

NEWMAN, M. E. J. Finding community structure using the eigenvectors of matrices. Physical Review E, v. 74, n.3, p. 19, set. 2006. 
PINHO, J. A. G. Investigando portais do governo eletrônico de estados no Brasil: muita tecnologia, pouca democracia. Revista de Administração Pública, v. 42, n.3, p.471-93, 2008.

PIRES, V. et al. Dossiê campo de públicas no Brasil: definição, movimento constitutivo e desafios atuais. Administração Pública e Gestão Social, v. 6, n. 3, p. 109-167, 2014. Disponível em: http://hdl.handle.net/11449/124598. Acesso em: 31 jan. 2020.

PRZEYBILOVICZ, E.; CUNHA, M. A.; COELHO, T. R. O desenvolvimento dos estudos sobre governo eletrônico no brasil: um estudo bibliométrico e sociométrico. Revista Electronica de Sistemas de Informaçao, v. 14, n. 3, p. 3, 2015.

R CORE TEAM. R: A language and environment for statistical computing. Vienna, Austria: R Foundation for Statistical Computing, 2017. Versão 3.4.3, 30 nov. 2017. Disponível em: https://www.R-project.org/. Acesso em: 25 maio 2018.

SAMPAIO, R. C.; BRAGATTO, R. C.; NICOLÁS, M. A. A construção do campo de internet e política: análise dos artigos brasileiros apresentados entre 2000 e 2014. Revista Brasileira de Ciência Política, n. 21, p. 287-322, 2016.

SANTOS, J. G. B., ALDÉ, A. \& SCHWAMBACH, A. C. F. Panorama das teses e dissertações brasileiras envolvendo internet e política de 1995 a 2014. In: ENCONTRO ANUAL DA ANPOCS, 40., 2016, Águas de Lindóia. Anais [...].

UNITED NATIONS. United Nations E-Government Survey 2014. New York: UN, 2014.

WHITE, Howard D.; GRIFFITH, Belver C. Author Cocitation: A Literature Measure of Intellectual Structure. Journal of the American Society for Information Science, v. 32, n. 3, May 1981, p. 163-171.

Artigo recebido em: 2020-01-31

Artigo reapresentado em: 2020-03-26

Artigo aceito para publicação em: 2020-04-19 